\title{
Academic Purpose and Need for Motivation in Writing Education for International Students
}

\author{
Hee-Eun $\left.A n^{1}\right)$
}

\begin{abstract}
This study focuses on the motivation and self-efficacy of learners for successful academic writing of international students for academic purposes. Writing is a complex activity that requires thought and expression. This leads to anxiety and obstacles to writing even in Korean university students in Korea. Therefore, it is a difficult process for foreign students who write Korean universities in foreign languages. The purpose of this study is to discuss the motivations of learning motivation and motivation for international students to have high motivation and self-efficacy. These results can be a positive motivation for writing so that the goal of university writing can be the process of realizing sustainable long-term goals.
\end{abstract}

Keywords: Academic Purposes, International Students, Motivation, Internal Motivation, External Motivation, Self-efficacy

\section{Introduction}

This study aims to examine the necessity of positive motivation approach for the successful writing of foreign students with academic purposes, and also to make suggestions.

Min Jeong Jo et al conducted a needs survey on the difficult or necessary language area in college course targeting total 62 students of a college, and the most difficult area was revealed as writing(48.4\%), speaking(22.6\%), listening(8.1\%), and reading(6.5\%) in order[1]. As an ability to communicate and introspect to the foreign students with academic purposes, the writing could be the foundation of college scholastic ability to independently express their thinking. In case of this writing, most of the foreign students receive the integrated education of writing, speaking, listening, and reading for the goal of understanding Korean language in a college-affiliated language institute before entering the school. At this time, what they learn is the contents necessary for daily life focusing on themes and functions. On the other hand, the academic purpose-writing which is learned by foreign students after entering school has duties

Received(September 18, 2019), Review Result(1st: October 11, 2019, 2nd: November 19, 2019), Accepted(January 30, 2020)

1) (Professor) 49104 Dept. Korean Language Education as a Foreign Language, Kosin Univ., 194, Wachi-ro, Yeongdo-gu, Busan, Korea

email: anheeeun@hanmail.net 
to cultivate the level of citizenship in society and also to enhance each individual's thinking ability as the core of college basic education[2], and also aims to achieve the desirable growth based on the self-introspection through an ability to mutually regulate their own opinions with others' and expressive behavior. Thus, the Korean writing learned before entering school aims for the understanding of linguistic enhancement for performing the primary function, and based on this, it is regarded as the sub-system of 'academic purpose'-writing which is the system in which the 'academic purpose'-writing is established. After entering school, the foreign students with academic purposes complete the writing course as a required liberal arts course. And the needs and necessity of Korean writing education are gradually increasing. As the writing ability is directly connected to the academic efficacy, it could be a cause for academic underachievement or dropout[3]. Therefore, in the academia, there have been continuous researches emphasizing the importance of writing for the foreign students with academic purposes.

The objective of this study is to make suggestions for the foreign students with academic purposes to find the efficacy of writing through motivation as a strategy for successful writing. Thus, targeting the students taking the course 'Creative Thinking and Writing' which is a required liberal arts course of a university in Busan where the researcher provides lectures, this study aims to analyze the writings under the theme of concerns about writing, to examine their problems, and then to suggest the measures for them.

\section{Theoretical Background of Motivation}

Writing is a relatively high level of activity that is required for complex and elaborate expressions as a complex and difficult behavior of expression. The reality of the current college writing given to foreign students does not satisfy it though. The reason for this could be shown as various variables such as poor Korean language proficiency or insufficient college scholastic ability, or absence of self-confidence as a foreign student even though the record of the Test of Proficiency in Korean(TOPIK) is higher than the intermediate level. That is why most of the foreign students focus more on the language abilities such as vocabulary, grammar, spelling, and connection of sentences even after entering college, which does not accord with the goals of education in the major and required areas of college. Jakobovits said that the success rate of foreign language learning would include the efforts \& motivation( $33 \%$ ), aptitude(33\%), intelligence(20\%), and others(15\%)[4]. Such results of this study show that the affective factors such as efforts and motivation precede the intelligent ability based on the 
linguistic elements and knowledge. Therefore, as the motivation-related elements such as goals of learning, needs, and self-efficacy have huge effects on the learners, the foreign learners should be accompanied by the intrinsic motivational factor.

\subsection{Motivation and Learning Motivation Theory}

\subsubsection{Types of Motivation: Extrinsic Motivation and Intrinsic Motivation}

Generally, the learning-related motivation is divided into extrinsic motivation and intrinsic motivation. First, as a motivation caused by external causes for human behavior, the extrinsic motivation focuses on something extrinsic and environmental such as proper reward, social, pressure, and punishment[5]. The extrinsic motivation is divided into autonomous extrinsic motivation and heteronomous extrinsic motivation. After a student decides the extrinsic reward for oneself, the student conducts an act for it, which is the autonomous extrinsic motivation. The heteronomous extrinsic motivation is to conduct an act to get a praise and pressure from other people[6]. On the other hand, sharing the needs, cognitions, and emotions of human by vitalizing, directing, and maintaining an act through intrinsic process, the intrinsic motivation focuses on something personal. At this time, the needs are the individuals' intrinsic condition essential for maintaining a life and enhancing the growth and happiness. The cognitions mean mental events such as thinking, belief, expectation, plan, strategy, and self-concept while the emotions are viewed as an alliance of emotions, arousal, goals, and expressive responses towards the important events of our lives.

The most important thing about college writing to the foreign students with academic purposes, might be the successful academic performance by discovering the intrinsic pleasure of writing. This intrinsic motivation enhances the effects of learning by arousing interest, curiosity, and immersion of writing, and helps the students to have the satisfaction and accomplishment, which eventually makes them challenge the higher-level of abilities. According to Reeve, once a person is intrinsically motivated, the person devotes oneself to the thematic and interested area, aims to improve one's abilities by voluntarily and creatively putting efforts and acting, deeply and conceptually processes information, shows the high level of task commitment, and experiences the high level of positive emotions, vitality, and wellbeing. Like this, the intrinsic motivation brings about the qualitative improvement of each individual life[7].

\subsubsection{Influence Factor of Motivation: Self-efficacy}


Self-efficacy has effects on conducting an act, putting efforts, and making it sustainable. Bandura defined the self-efficacy as one's judgment of abilities to organize/perform certain acts necessary for performing a special task[8]. In relation to this, Yun Hee Seung viewed it as a judgment of one's abilities to organize/execute a process of acts required for the performance[9]. The individuals with self-belief or self-efficacy participated more actively in writing activity, and also maintained the writing activity for longer than the individuals without it. Thus, the alternative for successful writing is to have the self-efficacy, which could be based on the positive motivation.

According to Dale $\mathrm{H}$. et al, the actual result which is the result-expectation belief in how a person act, is decided by self-efficacy. He viewed that the effects of self-efficacy on the motivation would be very huge. Once the self-efficacy is cognized as high for oneself, each individual would actively participate in the task that could enhance the development of one's abilities. On the other hand, in case of the students with low self-efficacy, they even had no opportunities to get feedbacks that could reduce the perception of negative self-efficacy by avoiding the task itself[8]. Therefore, if the foreign students have the high self-efficacy of writing, they would perform the sustainable writing by more cognitively participating in even difficult tasks of writing. Self-efficacy formed in each individual contributes to deciding the quality of functions in diverse methods. In other words, it is because they put efforts and show some patience for performing a certain act well. Therefore, it is very important for the foreign students to positively perceive themselves in relation to writing, and through this high self-efficacy, the learning, coping, performance, and achievement could be enhanced and improved.

\section{Research Methods}

\subsection{Information of Learners and Research Procedures}

The research subjects were total 35 students(W25:China21,Russia3,Japan 1/M10:China9,Saudi1) participating in the course 'Creative Thinking and Writing' which was a required liberal arts course as the first-year foreign students of a four-year-course college in Busan. As the students who resided in Korea for minimum of six months or three years or more, those students were in the Level3 - Level5 of TOPIK.

This study asked the foreign students to descriptively write down their concerns about Korean writing as a foreign language, and the solutions to them. This research was conducted 
in the first class of the course 'Creative Thinking and Writing', and the foreign students were asked to freely write down their own feelings and thinking about writing.

\subsection{Research Results}

All the 35 students taking the course 'Creative Thinking and Writing' were experiencing difficulties in writing, and they already knew about their problems. The significance of this result is that the students with the Level3 or up of the Test of Proficiency in Korean(TOPIK) already know about their own problems with writing. To examine the students' problems, the results of analyzing their descriptive writings could be enumerated as follows.

[Table 1] Writing Problems for International Students

Lack of confidence, vocabulary, grammar, expression problems, sentence composition, quantity problems, difficulty finding the subject / title, difficulty in translating Korean into the native language, difficulty in spelling, spacing, differences in the native language and word order, Difficulty in exaltation, difficulty with awkward sentences, problems with sentence concatenation, problems with lack of knowledge, problems with mixed spoken and written forms

What should be the most noticed in the result above is the absence of self-confidence. Total 21 students of those 35 students pointed out the absence of self-confidence in writing as the biggest reason.

"When writing Korean texts to foreigners, I am not confident in thinking that it is a foreign language and writing in my native language is easy, but writing in Korean is difficult. And it's hard to fill up with what you don't know how to get started"(W, China, Topic Level 3)

"I can't be sure about the topic before writing. Many times you don't understand what a title requires. It is different to think because I am a foreigner. So when I write in Korean, I become less confident." (W, China, Topic Level 4)

Those foreign students above expressed the absence of self-confidence when writing in Korean, and revealed that they were facing difficulties from the beginning of writing. In the aspect of attitude towards writing, a great number of students cognize the absence of self-confidence in Korean writing for themselves. Just as the theories examined earlier, having 
the intrinsic/extrinsic motivation or self-efficacy is very important in the process of achieving goals. For the successful writing of foreign students with academic purposes, these motivations should be enhanced. Such high self-efficacy is realized in the process of achieving goals, and it is easy to judge when the degree of goal achievement is short-term or concrete. In the beginning, the foreign students feel difficult in Korean writing which is performed in college course, or they doubt about their own abilities to be able to achieve the goals. However, such difficult goals provide more information about students' learning ability than easy goals, so that eventually, it is effective for the improvement of self-efficacy. If the learners believe that they could maintain the level of efforts necessary for the success, the self-efficacy would be highly maintained.

The absence of self-confidence has negative effects on the issues related to theme, sentence expression, and contents of writing. According to Bandura, for the judgment of self-efficacy in academic situations, there are actual experience, vicarious experience, linguistic persuasion, and physiological arousal, and the actual experience as the first factor is the essential source of the past success and failure[8]. Even though those students as the research subjects had learning experiences in Korean language for more than six months at least before entering school, with the ability as higher than the intermediate-level in the Test of Proficiency in Korean(TOPIK), they showed very low self-efficacy in which they could not believe in themselves about the most basic parts such as vocabulary, grammar, word spacing, and sentence writing with the use of grammar and connective words. Their anxiety about writing, incompetence of themselves, uncertainty in the completion of tasks, and a sense of failure are highly possible to be maintained in the sustainable state of writing study in the future. Therefore, the students with academic purposes need to have the process for increasing their self-confidence and relevant self-efficacy before having effective learning strategies for flexible ways of thinking and active data processing through intrinsic motivation.

\section{Suggestions and Conclusions}

With the increased interest in writing education at college liberal art education, there have been more and more interest and researches on it. However, the writing course of many colleges focus on the practical writing. This kind of writing is fragmentary, and its effects cannot be lasting for a long time. Also, in case when emphasizing it too much, there could be an extreme phenomenon following only mechanical forms.

Thus, this thesis suggests the self-expressive writing for helping the foreign students with 
academic purposes to get successful results. The self-expressive writing is a type of writing mainly aiming to communicate and explore the writer's own experience, to come up with his/her own opinions about a certain object, and to express his/her own responses. In other words, it is about writing focusing on one's own living experience and then describing one's own thinking or feelings about it. Britton said that the self-expressive writing would be the form of writing close to ego and more personal such as letter, journal, personal essay, and autobiography[10]. Compared to other types of writing, this writing is extremely personal with almost no restriction of writing form or custom, so that the feelings about one's experiences or events could be freely described. Especially, in case of foreign students, they could get familiar with writing by introspecting their lives and experiencing the writing for healing themselves after getting out of the language form/system such as grammar, expression, and word spacing. The self-expressive writing could establish the identity, heal painful wounds from the past, and then design the better future based on the experience in oneself. The students could be properly selected and expressed in accordance with the purpose or contents of self-expressive writing[10]. Thus, this type of writing could be the most proper measures that could give the motivation from the most familiar thing to each individual student through interest, instead of fear of failure and anxious emotion of writing.

The objective of this study was to suggest the strategies to the foreign students with academic purposes for high self-belief and sustainable writing after getting out of the low academic motivation and low self-efficacy of Korean writing as a foreign language. Regardless of the goals of learning in college literary arts/major writing, the learners cannot get out of their goals for linguistic knowledge. And the absence of their self-confidence in writing is led to the low self-efficacy and low motivation, which becomes a cause for the academic failure. Therefore, this study suggested the self-expressive writing in which the foreign students as a subject could have diverse thinking and easily write by positively and actively participating in the writing of college course. The limitation of this study is the 35 subjects, and it is difficult to generalize that all foreigners have low motivation to write. In addition, there is a limit to reliability because the data of students have been described and reviewed. It is also a pity that the failure was suggested only as "self-expressive writing." However, I think it is worthwhile for the international students to have a lack of self-confidence in writing, to identify the problems and to suggest solutions. Subsequently, further studies such as self-expression writing should be conducted to verify whether the self-expression writing is effective in inducing foreign students' writing motivation and improving their writing ability. 


\section{References}

[1] Min Jeong Jo, Hyun Kang Kim, Young Bok Jin, Sung Soo Kim, A Research on the Compilation Plan of College Writing Textbook for Foreign Students-on the basis of demanding survey, Grammar Education, (2013), Vol.18, pp.209-240.

[2] M. Y. An, Writing Empathized with the Times - critical writing practice, The Korean Journal of Literacy Research, (2016), No.17, pp.71-94, UCI : G704-SER000002684.2016..17.002

[3] Ju Mi Lee, A Study on Education components of cognitive in Korean writing process, Korean Society for Cultural Convergence, (2016), Vol.38 No.4, pp.329-351.

[4] Jakobovits, L. A, Foreign Language A Psychological Analysis of the Issues, Rowley, Newbury House, (1970)

[5] Won Ho Cho, Psychology in School Education, Seoul: Kookmin University Press, (2005)

[6] Jae Seung Lee, An study on the factors and instruction of writing motives, Korean Society for Elementary Language Education, (2007), No.34, pp.325-346, DOI : 10.22818/jeke.2007...34.325

[7] Johnmarshall Reeve, Understanding of motives and emotions, John Wiley \& Sons, Ins, (2015)

[8] Dale H. Schunk, Paul R. Pintrich, Judith L. Meece, Motivation in Education, (Research and support), Translator: J. H. Shin, Seoul: Hakjisa, (2013), pp.243-245.

[9] Yun Hee Seung, A Study of Music Class Based on Learning Motivation Theory, The Journal of Learner-Centered Curriculum and Instruction , (2015), Vol.15 No.7, pp.357-382, UCI : G704-001586.2015.15.7.018

[10] Suk Ki Choi, Educational Implication of Expressive Writing, Writing Research, (2007), Vol.5, No.5, pp.205-239. 